Eixo Temático: Processos de Ensino-Aprendizagem

\title{
ET-06-012 \\ OFICINAS COMO UMA PRÁTICA PEDAGÓGICA FACILITADORA DA APRENDIZAGEM NO ENSINO DE GENÉTICA
}

Fernanda Stefanny Lima Sobrinho ${ }^{1}$, Mayara Camila Santos Silva ${ }^{1}$, Aline Bruna da Silva ${ }^{1}$, Natanielle de Oliveira Gomes², Averlane Vieira da Silva², Rubens Pessoa de Barros ${ }^{3}$

${ }^{1}$ Bolsistas do PIBID - Programa Institucional de Bolsas de Iniciação à Docência e graduandas em ciências biológicas pela Universidade Estadual de Alagoas - UNEAL.

${ }^{2}$ Bolsista do PIBIC - Programa Institucional de Bolsas de Iniciação Científica e graduanda em ciências biológicas pela Universidade Estadual de Alagoas - UNEAL.

${ }^{3}$ Coordenador do PIBID e Professor do Departamento de Ciências Biológica na Universidade Estadual de Alagoas - UNEAL/Campus I.

http://dx.doi.org/10.21472/congrebio2016.et-06-012

\section{RESUMO}

O presente trabalho relata a experiência vivenciada na Escola Estadual de Educação Básica Professora Izaura Antônia de Lisboa - EPIAL, localizada no município de Arapiraca AL, que dispõe, principalmente de aulas teóricas, não sendo tão atrativas aos alunos. Mediante a atuação dos acadêmicos em licenciatura de ciências biológicas, bolsistas do Programa Institucional de Bolsas de Iniciação à Docência - PIBID foi proposto trabalhar estratégias de aprendizagem para o ensino de genética, conteúdo que se apresenta como um dos mais complicados e de baixo rendimento escolar no ensino de Biologia. Tais estratégias tiveram enfoque nas aulas práticas experimentais, que tanto aconteceram no auditório da referida escola com a aplicação de um jogo, intitulado como Show da Genética, quanto no laboratório de ciências com a utilização da prática da Tipagem Sanguínea. As aulas práticas são de suma importância no âmbito escolar, pois servem como suporte para as aulas teóricas, onde se obtém uma melhor compreensão dos conteúdos ministrados em sala e possibilita o desenvolvimento de conceitos científicos, permitindo assim, que o aluno aprenda a abordar objetivamente o seu mundo e assim desenvolva problemas complexos. Ambas as práticas mostraram eficácia no processo de aprendizagem em genética, permitindo que os alunos participassem ativamente na construção do seu próprio conhecimento, deixando-os mais à vontade para participar, levandoos a refletir, avaliar, propor sugestões e resoluções de problemas sobre os conceitos estudados, contribuindo assim no processo de ensino-aprendizagem.

Palavras-chave: Práticas; Genética; Âmbito Escolar.

\section{INTRODUÇÃO}

A realidade da educação básica brasileira, particularmente, na rede pública de ensino é um dos assuntos mais debatidos na sociedade atual, onde usualmente os conteúdos de biologia e ciências são desenvolvidos com base nos livros didáticos e o conhecimento é repassado como algo já pronto, e a metodologia ainda é centrada no professor, com a maioria das aulas expositivas, conduzindo mais à memorização que ao desenvolvimento do raciocínio lógico e formal, deixando de proporcionar a curiosidade e o despertar para o conhecimento (SOUSA SOBRINHO, 2009).

A aprendizagem não se dá pelo fato de ouvir e folhear o caderno, mas de uma relação teórico-prática, com intuito não de comparar, mas sim de despertar interesse aos alunos (ZOBOLI, 1994), desenvolvendo conceitos científicos, permitindo assim, que o aluno aprenda a 
abordar objetivamente o seu mundo e assim desenvolva problemas complexos, gerando então discussões e melhor aproveitamento das aulas.

As dificuldades encontradas em sala de aula por muitos professores, principalmente os da disciplina de biologia, em abordar os conteúdos disciplinares de tal forma, que faça o aluno sentir interesse pela disciplina e tentar minimizar os baixos níveis de aproveitamento dos mesmos, uma das alternativas visadas tem sido a utilização de jogos didáticos e práticas experimentais, tanto no âmbito da sala de aula como em laboratórios (REGINALDO et al., 2010).

Dentre os diversos assuntos de biologia, a genética se apresenta como um dos mais complicados e de baixo rendimento escolar no ensino e Campos et al. (2003) discutem o fato de que o ensino de genética envolve conceitos abstratos, de difícil compreensão pelos alunos, na qual são necessárias atividades práticas que auxiliem no aprendizado, como complementação dos conceitos teóricos. Catarinacho et al. (2011), frisa que a dificuldade no ensino de Genética deve-se principalmente por ser um tema de difícil assimilação e que demanda um alto nível de abstração por parte do aluno, fazendo com que, muitas vezes, ele se sinta desmotivado a aprender tal assunto.

A falta de conexão entre a genética e o cotidiano dificulta o aprendizado desse tema tão importante. Isto torna necessário o desenvolvimento de estratégias e tecnologias de ensinoaprendizagem que auxiliem o professor na tarefa de estimular os estudantes para o conhecimento sobre o mesmo, bem como sua relação com a vida cotidiana que possibilita o despertar do aluno para a conscientização da aplicabilidade desta Ciência na vida das pessoas (KIMURA et al., 2013).

É por essa razão que as atividades práticas de genética são de extrema importância para que o aluno possa compreender, interpretar e empoderar-se do conteúdo apresentado. Além disso, as práticas despertam o interesse do educando por tratá-lo como agente, motivando a observar, interpretar, formular hipóteses e despertar seu julgamento crítico, além de despertar o interesse pelo conhecimento científico (BARBOSA e BARBOSA 2010; PIATTI et al., 2008).

Diante deste quadro de referência é neste momento que surgem os programas de aperfeiçoamento docente de formação inicial e continuada, como o PIBID (Programa Institucional de Bolsa de Iniciação à Docência) que é uma política de Estado fomentada pela Capes e implantada nos cursos de licenciaturas, que visa integração dos alunos no ambiente da educação básica, possibilitando a estes, uma formação plena na área da docência.

\section{OBJETIVO}

Retratar de forma dinâmica e diversificada o ensino de genética no ensino médio, assumindo características diferenciadas no processo de aprendizagem dos discentes, além de envolver e retirar os professores da situação de meros conhecedores de determinados conteúdos, para torná-los instigadores de ideias, pensamentos, atitudes e ações.

\section{METODOLOGIA}

O presente estudo foi realizado mediante intervenções práticas, proposta e adaptadas pelas bolsistas do PIBID/Ciências Biológicas da Universidade Estadual de Alagoas - UNEAL. Tais intervenções foram intituladas como Show da Genética e Tipagem Sanguínea, e executadas com alunos de uma das turmas de $3^{\circ}$ ano do Ensino Médio da Escola Estadual Professora Isaura Antônia de Lisboa-EPIAL, localizada no município de Arapiraca - AL, devido à necessidade de se compreender as recentes tendências do ensino de Genética.

O jogo Show da Genética foi baseado no programa de TV "Show do Milhão" do Sistema Brasileiro de Telecomunicações (SBT), foi realizado no auditório da referida escola, no tempo de duas aulas (50 minutos cada), perfazendo um total de aproximadamente 40 alunos. $\mathrm{O}$ mesmo trata-se de um jogo com perguntas objetivas, conforme os assuntos abordados pela professora regente, tornando dinâmico o conhecimento adquirido. Para dar dicas aos 
participantes, conforme as regras do jogo, dois alunos foram convidados para fazer parte da mesa junto com duas universitárias. Foram utilizados recursos midiáticos, contando com o auxílio de notebook, data show e caixa de som, disponibilizados pela escola. Foi proposto a separação da turma em dois grupos, para promover uma competição, instigando a participação dos alunos presente.

A experiência sobre a Tipagem Sanguínea foi realizada no Laboratório de Ciências da escola em questão, com duração de três aulas, contou com participação de 40 alunos. Na mesma foram realizados testes para descobrir o tipo sanguíneo e $\mathrm{Rh}$ dos alunos voluntários, para eficácia da prática fizemos uso de alguns materiais como, lancetas, lâminas de vidro, luvas, álcool, algodão e reagentes como ANTI-A, ANTI-B e ANTI-D.

Após as intervenções foram aplicados questionários para testar a praticidade e eficácia das práticas.

\section{RESULTADOS E DISCUSSÃO}

Através das intervenções descritas foi possível constatar o caráter motivador da metodologia empregada, visto que houve grande entusiasmo dos alunos em participar ativamente das situações propostas.

Após a análise dos questionários, verificou-se que $92,5 \%$ dos alunos classificaram os assuntos de genética como difíceis (Gráfico 1). E Vilela (2007) conta que essa problemática se deve em grande parte ao não preparo adequado do docente que ministra a disciplina, pela falta de associação dos conteúdos dados frente a realidade no qual o aluno está inserido e pela forma abstrata de como os conteúdos são abordados em alguns livros didáticos.

\section{As intervenções realizadas facilitaram a compreensão no ensino da genética?}

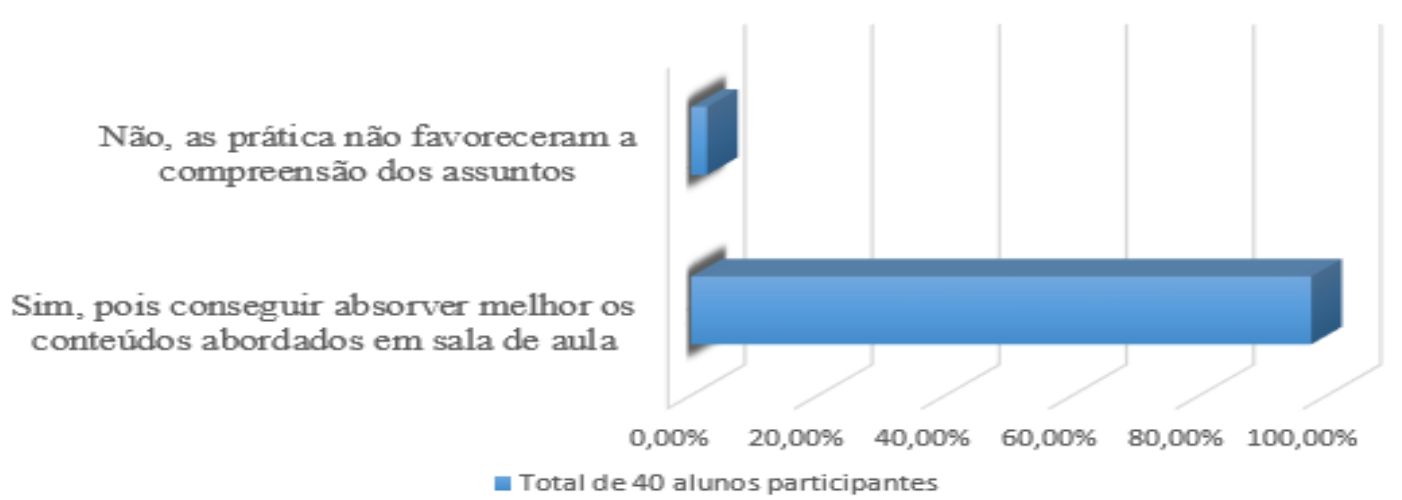

Gráfico 1. Opinião dos discentes quanto ao grau de dificuldade em genética.

Após questionar aos alunos sobre a compreensão dos conteúdos de genética, a maioria respondeu que através das práticas foi possível absorver melhor os assuntos vistos em sala de aula, conforme mostra o Gráfico 2. Havendo a comprovação que a relação teoria-prática, através do lúdico, experiências e outras estratégias de ensino têm propriedade de motivação, desempenhando um papel importante de despertar o interesse e a curiosidade para resolver problemas, como diz Silva (1998). 


\section{Como você classifica os assuntos de genética?}

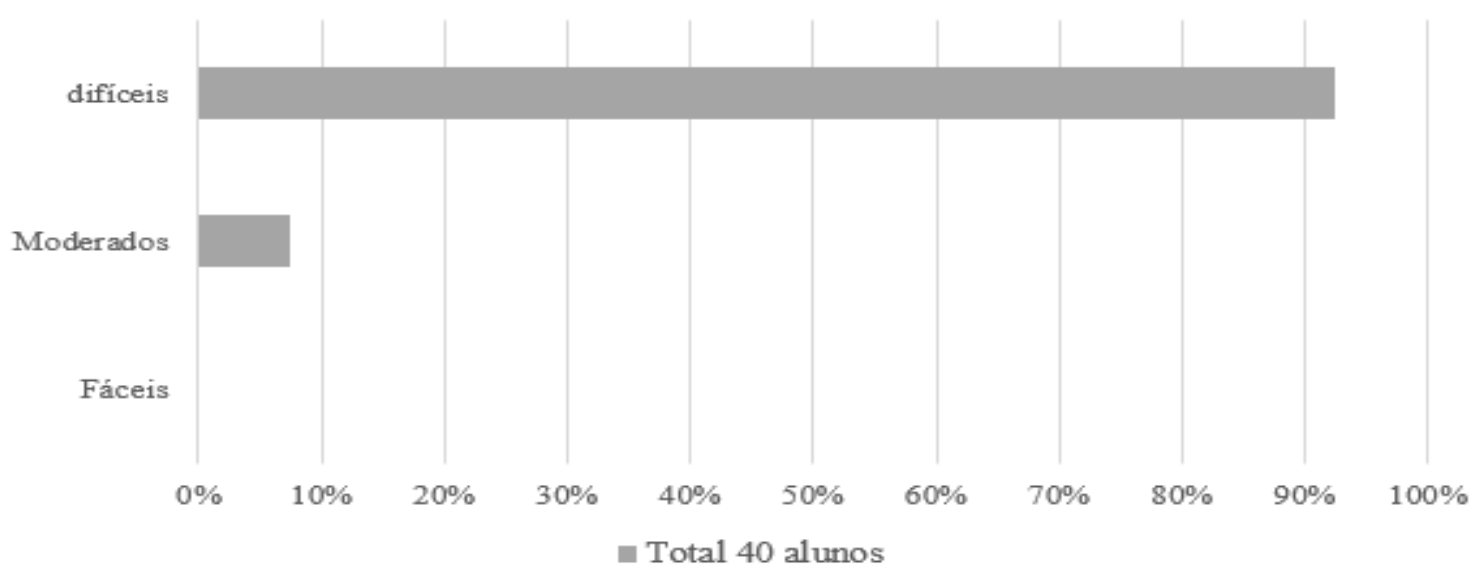

Gráfico 2. Opinião dos discentes sobre as intervenções realizadas.

Destaca-se, ainda, por meio do questionário realizado (Gráfico 3), a importância das aulas práticas para o desenvolvimento e a reflexão de estratégias metodológicas que resultem em melhorias para o ensino. Para facilitar este processo, é necessária a utilização de atividades e práticas dinâmicas, que auxiliem o entendimento dos conceitos, entre as quais instrumentos e ferramentas inovadoras como os jogos didáticos (HERMANN e ARAUJO, 2013).

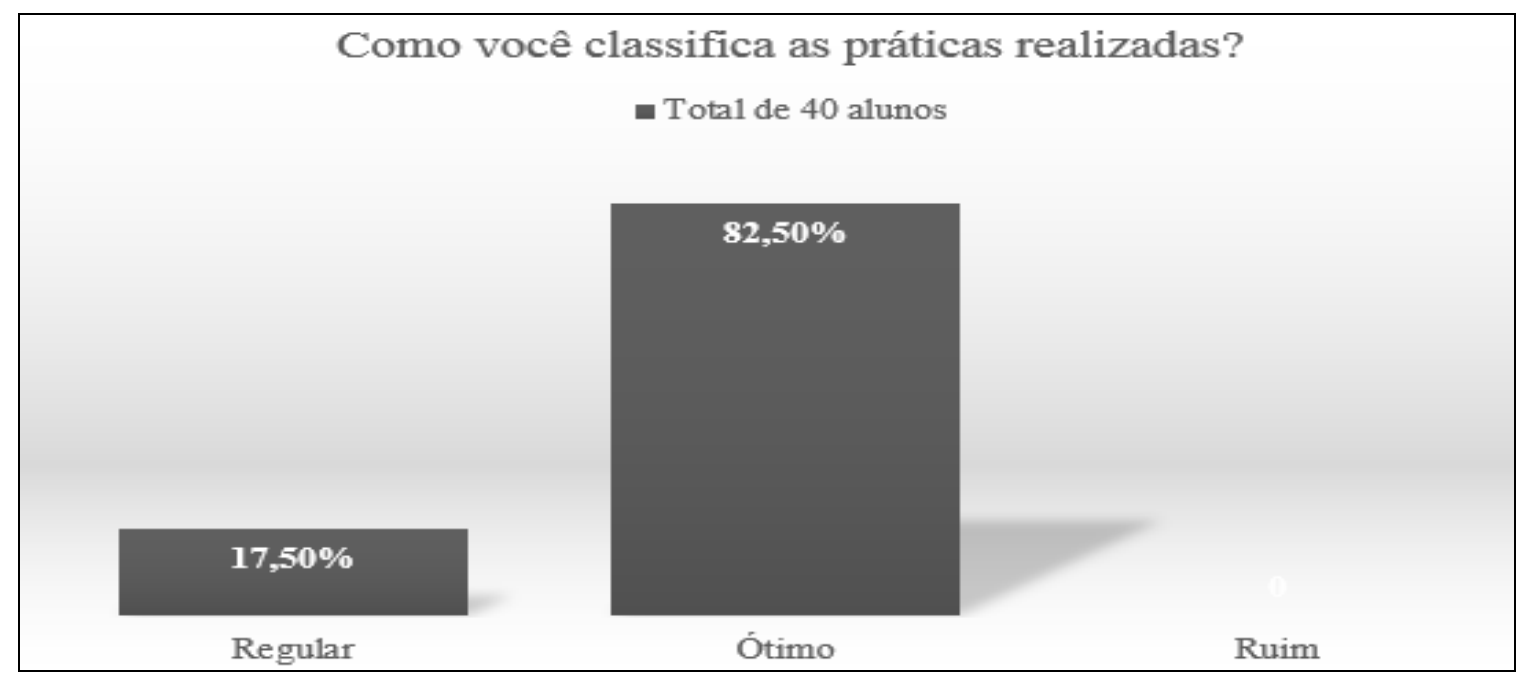

Gráfico 3. Opinião dos discentes quanto às práticas realizadas.

No geral, as duas aulas práticas explanadas mostraram-se bastante eficientes no processo de ensino-aprendizagem, visto que possibilitaram tratar conceitos genéticos em um novo contexto. A maioria dos alunos mostraram-se participativos e bastante motivado com as atividades realizadas.

Constatou-se que houve uma grande aceitação por parte dos alunos em relação às ações propostas pelo PIBID de Ciências Biológicas, o que mostra a necessidade de uma proposta diferenciada para o ensino de Genética/Biologia. 


\section{CONCLUSÃO}

Diante do que foi exposto, percebe-se que a utilização de oficinas como prática pedagógica facilitadora da aprendizagem, proporciona um diferencial ao modelo de ensino tradicional, essas atividades deram espaço para uma melhor relação entre professor e aluno, deixando o aluno mais à vontade para participar, levando-o a refletir, avaliar, propor sugestões e resoluções de problemas sobre os conceitos estudados, permitindo que os mesmos participem ativamente da construção do seu próprio conhecimento, ao mesmo tempo em que facilita o árduo trabalho do docente que é lecionar, devendo ter como consequência, o real aprendizado do aluno.

\section{AGRADECIMENTOS}

À Universidade Estadual de Alagoas - UNEAL, pela oportunidade de estudar em um Curso de Graduação/Licenciatura em Ciências Biológicas, carreira importante para o futuro do Brasil.

À Coordenação de Aperfeiçoamento de Pessoal de Ensino Superior - CAPES, através do Programa de Bolsas de Incentivo à Docência - PIBIB, através das bolsas do subprojeto de Biologia do Campus I da UNEAL.

\section{REFERÊNCIAS}

CAMPOS, L. M. L.; FELÍCIO, A. K. C.; BORTOLOTO, T. M. A produção de jogos didáticos para o ensino de ciências e Biologia: uma proposta para favorecer a aprendizagem. Caderno dos Núcleos de Ensino, p. 35-48, 2003. Disponível em:<http://www.mackenzie.br/fileadmin/Graduacao/CCBS/Cursos/Ciencias_Biologicas/1o_201 2/Biblioteca_TCC_Lic/2010/2o_2010/ANA_LUIZA_ABDO.pdf $>$. Acesso em: Acesso em: 25. abr. 2016.

BARBOSA, F. H.; BARBOSA, L. P. Alternativas metodológicas em Microbiologia: viabilizando atividades práticas. Revista de Biologia e Ciências da Terra, v. 10, p. 134-143, 2010.

CATARINACHO, R. L. O ensino de Genética com super-heróis: uma abordagem mutante na sala de aula. São Paulo: Universidade Presbiteriana Mackenzie, 2011. (Monografia). Disponível em: <http://repositorio.roca.utfpr.edu.br/jspui/bitstream/1/4407/1/MD_EDUMTE_2014_2_57.pdf>. Acesso em: 25. Abr. 2016.

HERMANN, F. B.; ARAUJO, M. C. P. Os jogos didáticos no ensino de genética como estratégias partilhadas nos artigos da revista genética na escola. 2013. Disponível em: <http://santoangelo.uri.br/erebiosul2013/anais/wp-content/uploads/2013/07/poster/

13461_290_Fabiana_Barrichello_Hermann.pdf>. Acesso em: 25. Abr. 2016.

KIMURA, A. H.; OLIVEIRA, G. S.; SCANDORIEIRO, S.; SOUZA, P. C.; SCHURUFF, P. A.; MEDEIROS, L. P.; BODMAR, C. G.; SARMIENTO, J. J. P.; GAZAL, L. E. S.; SANTOS, P. M. C.; KOGA, V. L.; CYOLA, P. S.; NISHIO, E. K.; MOREY, A. T.; TATIBANA, B. T.; NAKAZATO, G.; KOBAYASHI, R. K. T. Microbiologia para o ensino médio e técnico: contribuição da extensão ao ensino e aplicação da ciência. Revista Conexão UEPG, v. 9, n. 2, p. 254-267, 2013. Disponível em: <http://www.revistas2.uepg.br/index.php/conexao/ article/view/5516/3664>. Acesso em: 28. abr. 2016. 
REGINALDO, C. C.; SCHEID, N. J.; GÜLLICH, R. I. C. O ensino de ciências e a experimentação. Anais do IX ANPEDSUL (Seminário de Pesquisa em Educação da Região Sul). Caxias, RS. 2012.

SILVA, A. K. V.; BORBA, S. M. P. Jogos matemáticos: possíveis contribuições do lúdico à alfabetização de jovens e adultos. Proposta Curricular - Matemática. Ensino Fundamental. Núcleo de Ensino, Pesquisa e Extensão e Educação de Jovens e Adultos e em Educação Popular. UFPE, Recife, 1998.

SOUSA SOBRINHO, R. A Importância do ensino da Biologia para o cotidiano. Fortaleza: Faculdade Integrada da Grande Fortaleza, 2009. (Trabalho de Conclusão do Curso).

VILELA, M. R. A produção de atividades experimentais em genética no ensino médio. Belo Horizonte: Universidade Federal de Minas Gerais, 2007. (Monografia de curso de especialização).

ZOBOLI, G. Práticas de ensino, subsídio da atividade docente. São Paulo: Ática, 1994. 